\title{
Financial Inclusion and Health Shocks: A Panel Data Analysis of 36 African Countries
}

\section{Popoola, Oladayo Timothy ${ }^{1}$}

${ }^{\prime}$ Lecturer at the Department of Economics, Ahmadu Bello University, Zaria, Kaduna State, Nigeria.

Email:poladayo@mail.com Tel:234(0)8135745100

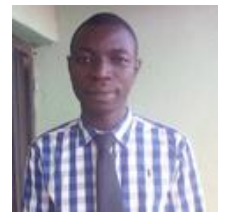

\begin{abstract}
Numerous evidence has revealed that African countries lagged behind in the attainment of healthrelated targets of the recent past Millennium Development Goals (MDGs). Perhaps because most Africans depend largely on out-of-pocket payments for medical-care services during their health shocks experiences. Evidently, this has been a great concern to both citizens and policy makers across Africa for a long time. Therefore, this paper investigates the impact of financial inclusion on health shocks in 36 African nations over the period of 2004 to 2016. The Fixed Effects model result indicates that increase in numbers of depositors with commercial banks proxy for financial inclusion is positive and significant to predict longevity in African nations. However, rise in population growth (the control variable) have a significant role to reduce average life expectancy in Africa. Thus, both African governments and their financial institutions may improve average life expectancy and human capital for more economic development through enhanced financial inclusion.
\end{abstract}

Keywords: Savings, Financial inclusion, Life expectancy, Africa, Panel data models.

JEL Classification: C23, E44, I15, N27.

Citation | Popoola, Oladayo Timothy (2019). Financial Inclusion and Health Shocks: A Panel Data Analysis of 36 African Countries Asian Journal of Economics and Empirical Research, 6(1): 45-51. History:

Received: 2 November 2018

Revised: 10 December 2018

Acrise 10 Decmber 2018

Accepted. 14 January 2019

Licensed: This work is licensed under a Creative Commons

Attribution 3.0 License (c))

Publisher: Asian Online Journal Publishing Group
Funding: This study received no specific financial support.

Competing Interests: The author declares that there are no conflicts of interests regarding the publication of this paper.

Transparency: The author confirms that the manuscript is an honest, accurate, and transparent account of the study was reported; that no vital features of the study have been omitted; and that any discrepancies from the study as planned have been explained.

Ethical: This study follows all ethical practices during writing.

\section{Contents}

1. Introduction 46

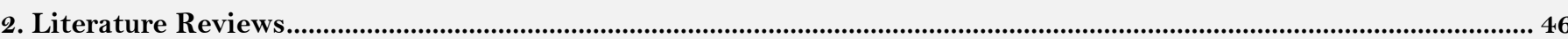

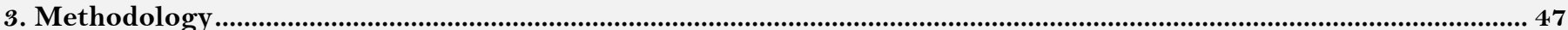

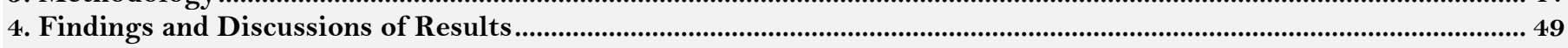

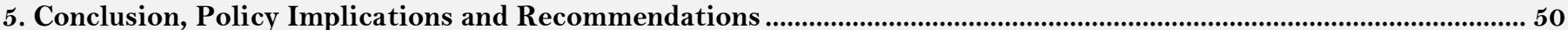

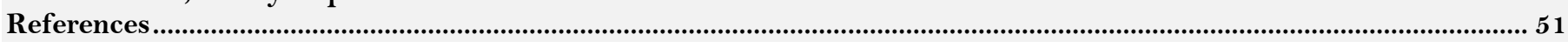




\section{Introduction}

Researchers to date have made considerable effort in estimating the effects of health insurance and spending on health outcomes in developing countries (Alam and Mahal, 2014; Witter et al., 2017; Dake, 2018; Dorfleitner and Rößle, 2018). However, little is known about the extent to which financial inclusion affects health shocks in Africa, where formal health insurance is hardly accessible and limited. Observably, African countries lagged behind in the attainment of health- and welfare-related of recent past Millennium Development Goals (Novignon et al., 2015) perhaps because most Africans depend largely on out-of-pocket payments for medical-care services during their health shocks experiences. Health shocks, the unpredictable illnesses that reduce longevity and that quickly diminish health status of individuals (Leivea and Xub, 2008) is often sudden events. This has been a great concern to both citizens and policy makers across Africa for a long time.

It also appears to be the biggest obstacle in achieving Sustainable Development Goals (SDGs); where several of the Africa's countries are still low-income nations due to high poverty prevalence and deteriorating welfare system (see Ellyne and Mahlalela (2017)). These factors also associated with African's citizens inability to access timely and appropriate healthcare services during the periods of health shocks. All citizens that experience health shocks are frequently affected by income loss because of their inability to work and needs for medical-care treatment payments. Therefore, it is pertinent to note that the first safety net that people rely on during health shocks is their own financial resources. Though people often employ different health financing strategies to cope with their health shocks. These strategies could be from the use of savings, borrowing funds from family and friends, selling of assets and properties, or take out loan probably using collateral. All these associated with the degree of financial inclusion in their societies

Perhaps, to improve longevity or average life expectancy at birth and achieve an efficient health system in Africa, improved financial inclusion is fundamental for easy access to credit and savings. This makes it imperative to understand how to facilitate healthcare financing through easy access to savings and credits to improve longevity for Africans. Thus, the purpose of this paper is to explore empirically the impacts of financial inclusion on health shocks; however, due to limited data availability on health shock, the study proxy average life expectancy at birth for health shock in 36 Africa countries (Algeria, Angola, Burundi, Benin, Burkina Faso, Botswana, Cameroon, Comoros, Cote d'Ivoire, Democratic Republic of Congo, Congo Republic, Cabo Verde, Ghana, Guinea, Gambia, Guinea-Bissau, Kenya, Lesotho, Malawi, Madagascar, Mali, Morocco, Mozambique, Namibia, Niger, Nigeria, Rwanda, Senegal, Sao Tome and Principe, Seychelles, Togo, Tunisia, Tanzania, Uganda, South Africa and Zimbabwe).

These nations vary in their level of total health expenditure, numbers of depositors with commercial banks per 1,000 adults, extent of financing healthcare, and average life expectancy. For instance, the average longevity ranges from a low of 44.5 years in Zimbabwe to a high of 63 years in Ghana for 2004 and 2016 respectively. Furthermore, the pursuit of the study is based on two interrelated factors; (i) equitable access to healthcare services during health shocks periods remain a big challenge in Africa; and (ii) timely healthcare financing improves longevity and economic activities. Therefore, the paper started with an introductory section followed by a review of related literature in Section two. Section three dwells on methodology, while section four presents the empirical findings. Section five concludes the paper with policy recommendations.

\section{Literature Reviews}

Health shock concern unpredictable illnesses that quickly diminish health status of individuals with great impact on the economic well-being of individuals (Leivea and Xub, 2008). It implies that health shock is a sudden event that requires attention. In developing countries, health shocks and illnesses from non-communicable diseases (such as, strokes, heart disease, cancers, diabetes, chronic lung and respiratory diseases) are on the increase over the recent years (WHO, 2018). Figure 1 depicts annual global deaths from various ill-health, where health shocks that leads to sudden illness from non-communicable diseases (NCD) alone responsible for over 36 million deaths per annual globally. Nearly half (17.7 million) of these yearly deaths are from cardiovascular diseases (stroke and heart diseases) only. Worse still, 9 million people die prematurely every year before the age of 60 from brief illness that associated with these diseases. While 8 million of deaths occurred in low- and middle-income countries most especially the Africa countries (WHO, 2018).

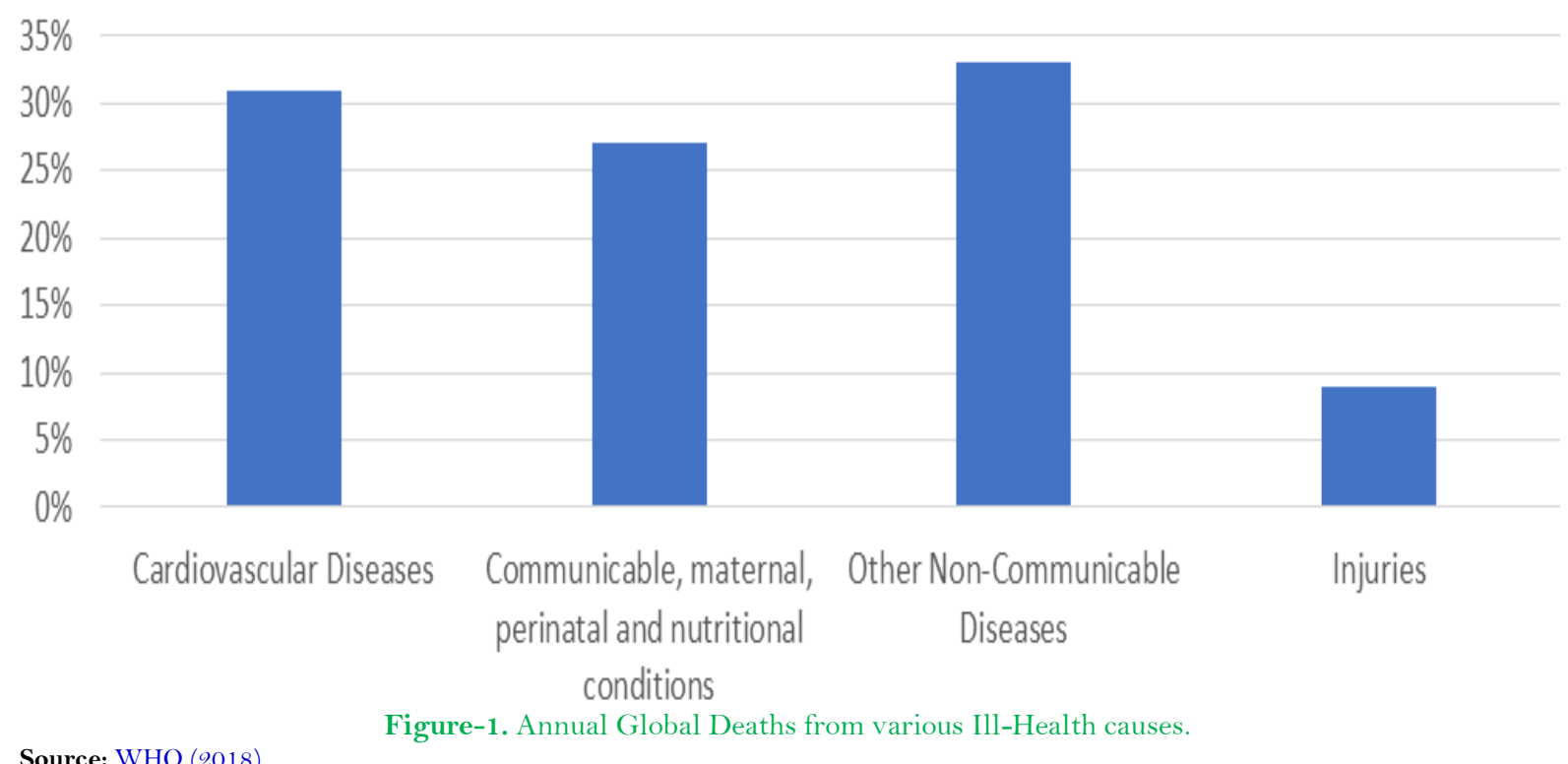

Source: WHO (2018). 
Africa region also has the highest prevalence of hypertension which affects $46 \%$ of adults aged over 25 years (WHO, 2017b). Further, heart disease and strokes are the $2^{\text {nd }}$ leading causes of chronic illnesses in Africa after malaria (WHO, 2017a). This is because most Africans still depend largely on out-of-pocket payments for medicalcare. Consequently, the unpredictable 'health shock' diminish longevity or the average life expectancy (at birth) of individuals, where Table 1 shows the comparative life expectancy across the regions of the world. The statistics shows that Africa continent performs relatively poorly against all others. Though the average longevity in Africa increased slightly from about 60 years in 2000 to about 66 years in 2015, compare to the global average of 67.6 and 71.7 years in 2000 and 2015 respectively.

Table-1. World Average Life Expectancy at birth (total).

\begin{tabular}{c|c|c|c|c|c|c|c}
\hline Year & $\begin{array}{c}\text { Global } \\
\text { Average }\end{array}$ & SSA & Middle East \& North Africa & $\begin{array}{c}\text { Africa } \\
\text { Average* }\end{array}$ & $\begin{array}{c}\text { OECD } \\
\text { members }\end{array}$ & $\begin{array}{c}\text { East Asia \& } \\
\text { Pacific }\end{array}$ & \begin{tabular}{c} 
North America \\
\hline $\mathbf{2 0 0 0}$
\end{tabular} \\
67.6 & 50.3 & 69.8 & 60.1 & 77.1 & 71.4 & 76.9 \\
\hline $\mathbf{2 0 0 5}$ & 69.0 & 52.7 & 71.0 & 61.9 & 78.2 & 73.1 & 77.8 \\
\hline $\mathbf{2 0 1 0}$ & 70.5 & 56.3 & 72.1 & 64.2 & 79.5 & 74.2 & 78.8 \\
\hline $\mathbf{2 0 1 5}$ & 71.7 & 58.9 & 73.1 & 66.0 & 80.3 & 75.1 & 79.1 \\
\hline
\end{tabular}

Source: Compiled from World Bank Development Indicator, 2018

*Computed from column 3 and 4.

Table 2 further indicates that most nations in Africa had low life expectancy (LE). For instance, the LE in Nigeria increased marginally from 46 years in 1995 to about 53 years in 2015, while Rwanda's LE rose from 31 years to 65 years during the same period (World Bank, 2018). For Ghana, her life expectancy rises steady from 1975 to 2015; where it rose from 50.8 years in 1975 to 56 years in 1990, and 61.4 years in 2015. Comparatively, the LEB in Nigeria is lower compared with Rwanda, Ghana and South Africa probably as a result of ill-health issues in the nation. Although the average life expectancy in recent years is merely higher than the Cote d'Ivoire.

\begin{tabular}{c|c|c|c|c|c|c|c|c|c|c}
\multicolumn{10}{c}{ Table-2. Comparative Average Life Expectancy at birth (total) in Africa. } \\
\hline Country & $\mathbf{1 9 7 5}$ & $\mathbf{1 9 8 0}$ & $\mathbf{1 9 8 5}$ & $\mathbf{1 9 9 0}$ & $\mathbf{1 9 9 5}$ & $\mathbf{2 0 0 0}$ & $\mathbf{2 0 0 5}$ & $\mathbf{2 0 1 0}$ & $\mathbf{2 0 1 5}$ & $\mathbf{2 0 1 6}$ \\
\hline Cote d'Ivoire & 47.7 & 50.7 & 52.6 & 52.6 & 49.5 & 46.7 & 47.7 & 50.1 & 51.9 & 53.6 \\
\hline Ghana & 50.8 & 52.3 & 54.1 & 56.7 & 57.5 & 56.9 & 58.7 & 60.6 & 61.4 & 63.7 \\
\hline South Africa & 54.2 & 56.9 & 59.9 & 62.1 & 61.4 & 55.8 & 51.5 & 54.4 & 57.4 & 62.8 \\
\hline Rwanda & 44.9 & 47.9 & 50.4 & 33.4 & 31.6 & 48.1 & 54.7 & 61.4 & 64.5 & 67.1 \\
\hline Cote d'Ivoire & 43.4 & 45.5 & 46.3 & 46.1 & 46.1 & 46.6 & 48.6 & 51.3 & 53.0 & 53.4 \\
\hline
\end{tabular}

Source: Compiled from World Bank Development Indicator, 2018.

These statistics shows that several African nations recorded low LE in the world. Meanwhile, a dominant strand of health financing literature (see: (Alam and Mahal, 2014; Witter et al., 2017; Dake, 2018; Dorfleitner and Rößle, 2018)). These studies have underscored the key role of financial inclusion in the process of assuring ease access, availability and usage of the formal financial system by all members of economy especially in periods of health shocks. Furthermore, considering the role of savings and access to credits towards healthcare accessibility cannot be downplayed. As pointed out by Grossman (1972) these can be viewed as ease of investments during sudden illnesses that reduce longevity and that quickly diminish health status of individuals.

\section{Methodology}

\subsection{Analytical Framework}

Grossman (1972) suggest that longevity and health status of individuals $\left(H_{t}\right)$ depreciate during their lifetime due to health shocks $\delta_{t}$, but such individuals can invest in their health to offset this depreciation or health shocks. That is,

where;

$$
H_{t}=\delta_{t} H_{t}+I_{t}
$$

$H_{t}=$ longevity or citizens' healthiness at current period;

$\delta_{t} H_{t}=$ health shocks or illness through diseases and sick-days;

$\delta_{t}=$ rate of depreciation; while

$I_{t} \quad=$ gross investment on health status.

This implies that:

$$
\Delta H_{t} / \Delta t=I_{t}-\delta_{t} H_{t}
$$

Where $\Delta H_{t} / \Delta t$ will always be positive when $I_{t}>\delta_{t} H_{t}$, that is, when citizens invest more in their health status $H_{t}$. On the other hand, $\Delta H_{t} / \Delta t$ will be negative anytime $I_{t}<\delta_{t} H_{t}$. Therefore, to improve $I_{t}$, Grossman (1972) opine availability of financial resources.

From the foregoing, the analytical foundation for this study is predicted on Grossman approach. The framework considers the role of investment in health status during health shocks. Schema 1 thus provides a lucid exposition of the transmission channels from financial inclusion during health stock to improve longevity in Africa. 


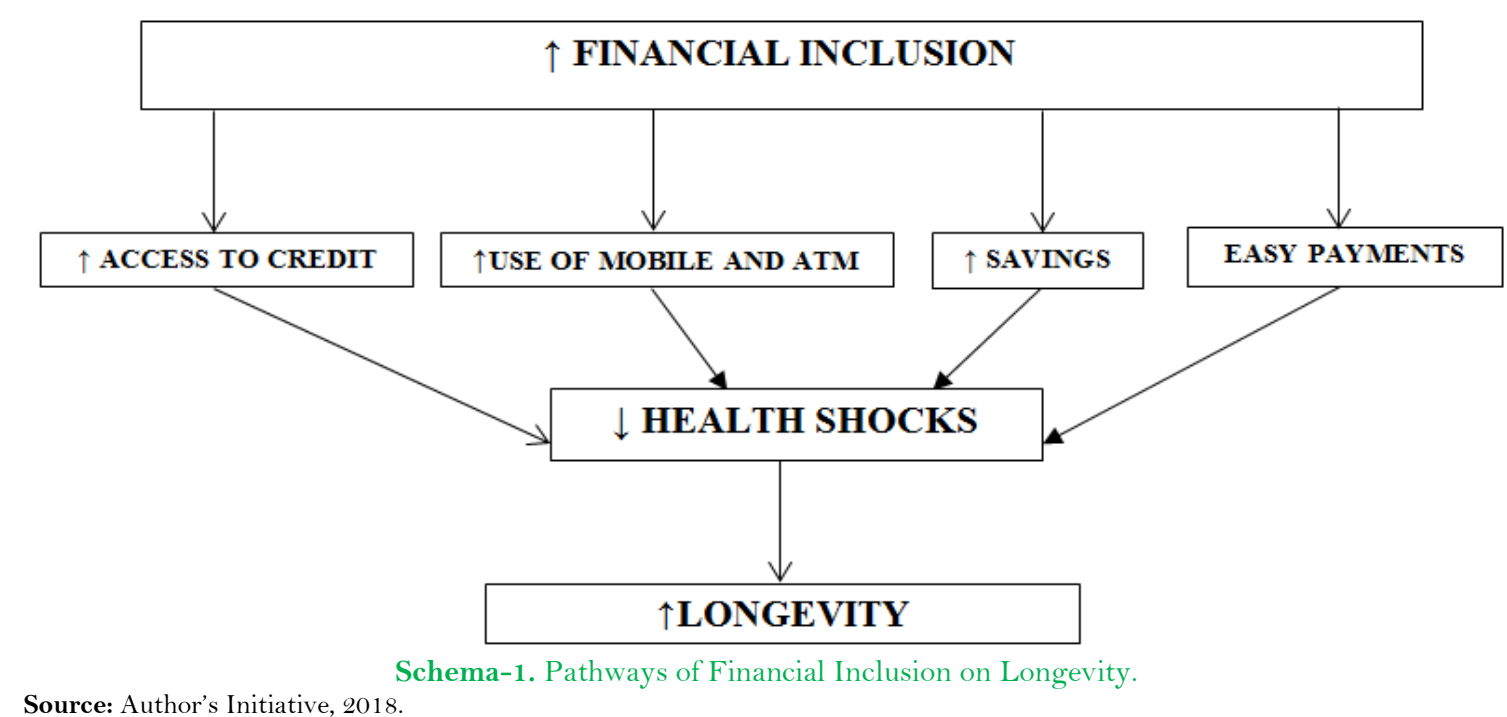

Notably, the arrow lines in Schema 1 show the direction of the flow of impact from financial inclusion to longevity. Ample recent empirical evidence indicated that an improved financial inclusion propels and play a vital role in promoting access to credit, use of mobile and ATM, savings and easy access to payments (see (Naceur et al., 2015; Dorfleitner and Rößle, 2018). The motivation for increased financial inclusion is to ensure all adults members of all nations to have easy access to extensive financial products, personalized towards their health needs and provided at reasonable costs (Okoroafor et al., 2018). Access to credit from family and friends or financial institutions is associated with good health (Leivea and Xub, 2008). For instance, a well-functioning financial system improves access to healthcare services by building a platform for providing credit and health-risk management products to people with a range of health-needs.

Savings also exert positive impact on longevity by reducing health-shocks. Quality savings play a vital role in promoting both direct and indirect capabilities of people to access healthcare services during health-shocks (Love and Peria, 2012). It impacts longevity directly through enabling the provision of financial resources via timely payments, and indirectly through enabling borrowing and granting access to new credits opportunities for the lowincome earners (Witter et al., 2017; Dake, 2018). Hence, an inclusive financial system is key to build a platform for financial institution to permits an easy broad-based access to financial services especially during health shocks periods. Without financially inclusion systems, the poor would rely on their inadequate savings (Naceur et al., 2015).

\subsection{Model Specification}

The model adopted for this study is in the spirit of the Grossman (1972). However, the specification of this study differs from the aforementioned in that the paper empirically estimates the impact of financial inclusion on longevity in 36 African nations. The model is specified as follows:

$$
H_{i t}=f\left(F I_{i t}\right)
$$

Where the subscript $i$ is the selected African nations and $t$ represents the time frame considered.

The paper relies on average life expectancy at birth (LEB) as a proxy for longevity. LEB refers to the average number of years an infant is expected to live if a mortality pattern at the time of birth remains constant in the future. It is the average-period that a person is expected to live as determined taking account of current economic situation. It also reflects the overall mortality level of a population and summarizes the mortality pattern that prevails across all age groups (WHO, 2017a). It also indicates the number of years an infant would live provided the patterns of mortality continues at the time of birth were to stay the same throughout his life. Hence, it is an important index of long life.

For financial inclusion in Africa (FI), the study employed the numbers of depositors with commercial banks per 1,000 adults; and population growth rate (PGR) as the control variables. From Equation 3, it implies that:

$$
L E B_{i t}=f\left(F I_{i t}, P G R_{i t}\right)
$$

Hence, the econometric model from Equation 4 is explicitly specified as:

$$
L E B_{i t}=\alpha+\beta_{1} F I_{i t}+\beta_{2} P G R_{i t}+\mu
$$

Where $\boldsymbol{\mu}$ is the error term assumed to satisfy the Gaussian white noise condition; $\boldsymbol{\alpha}$ is the intercept, $\boldsymbol{\beta}_{1}$ and $\boldsymbol{\beta}_{2}$ are parameters or slope of relationship for $\boldsymbol{F I}$ and $\boldsymbol{P} \boldsymbol{G} \boldsymbol{R}$ respectively. Apriorily, $\boldsymbol{F I}$ is expected to exert positive influence on longevity; while $\boldsymbol{P G H}$ is negatively related.

\subsection{Estimation Procedures}

The paper empirically investigates the impact of financial inclusion on longevity in Africa by employing panel regressions. Three regressions models were estimated based on the unobserved characteristics. These techniques were - pooled ordinary logistic (POL), fixed effects (FE) and random effects (RE). Since the intercept $\alpha_{i}$ is unobserved heterogeneity which is fixed for nations in Africa and $u_{i t}$ the residual. In estimating POL, $\alpha_{i}$ becomes a component of residual.

Thus, the composed residual is:

$$
v_{i t}=\alpha_{i}+u_{i t}
$$

However, $\beta s$ in POL can be inefficient because of the unobserved effect in $v_{i t}$. This generate serial autocorrelation; thus, robust test will be needed to deal with the issue. RE assume unobserved effect is unknown and can be captured by random variable and treated as part of $u_{i t}$. It also imposes more restrictive assumption than POL, because it includes the unobserved heterogeneity in $\boldsymbol{V}_{i t}$ to obtain consistent and efficient $\boldsymbol{\beta} \boldsymbol{s}$. For FE, the 
model assumes that $\boldsymbol{\alpha}$ varies but fixed over time. The basic idea of FE model is that a set of $\boldsymbol{\alpha}_{i t}$ can capture all the unobserved heterogeneity.

To check for the homogeneity or heterogeneity of the dataset, Breusch-Pagan Lagrange Multiplier test was employed. The null hypothesis $\left(\mathrm{H}_{\mathrm{o}}\right)$ of the test is homoskedasticity of countries in Africa, that is, POL might be the appropriate model. Notably, because of the potential of inconsistency of pooled regression for large observation bias, the study used the bias-adjusted variant of Breusch and Pagan Lagrange Multiplier (LM) test statistic (BALM) proposed by Pesaran et al. (1999). They showed that the BALM test has desirable finite sample properties, successfully control for size and maintains appropriate power when the repressors are exogenous and errors are normal. However, the BALM test statistic is only valid for static models unlike Pesaran et al. (1999) test statistic that extends to dynamic models.

\subsection{Data for the Study}

The sources of data for this study are annual data from WB (2018) for the period of 2004 to 2016. The study considered 36 African countries for which data on the variables of interest were readily available.

\section{Findings and Discussions of Results}

Table 3 shows some descriptive statistics on the numbers of depositors with commercial banks per 1,000 adults (NDCB) as proxy for financial inclusion, average life expectancy at birth (total) and annual GDP growth (\%) of the 36 African countries. The average numbers of depositors with commercial banks is 307,000 adults; Cabo Verde has the highest NDCB of 1,860,000 depositors in 2015, while Angola have the lowest NDCB of 369 depositors in 2004 among these African nations analyzed. Statistics on longevity indicates that the average life expectancy at birth is about 60 years old, where Algeria has the highest average longevity of 76 years while Zimbabwe has the lowest of 44 years.

Table-3. Descriptive Statistics of Variables.

\begin{tabular}{c|c|c|c|c|c}
\hline Variable & Observation & Mean & Standard Dev. & Min. & Max. \\
\hline LE & 468 & 59.86 & 7.11 & 44.57 & 76.08 \\
\hline FI & 468 & 307.12 & 367.53 & 0.37 & 1860.85 \\
\hline PG & 468 & 2.50 & 0.86 & -2.63 & 4.61 \\
\hline \multicolumn{2}{l}{ Source: Own Computation from Stata 13. }
\end{tabular}

On the other hand, the correlation matrix table presented in Table 4 reveal high direct correlation between numbers of depositors with commercial banks (FI) and longevity (LE). However, inverse relationship exists between population growth rate (PGR) and average life expectancy (LE). Overall, the correlation matrix table suggest that an increase in the numbers of depositors with commercial banks (the financial inclusion) is linked to improve average life expectancy in Africa.

Table-4. Correlation Matrix, 1990 to 2017

\begin{tabular}{c|c|c|c}
\hline & LE & FI & PG \\
\hline LE & 1.0000 & & \\
\hline FI & 0.5624 & 1.0000 & \\
\hline PG & -0.3844 & -0.5637 & 1.0000 \\
\hline
\end{tabular}

Source: Own Computation from Stata 13.

Table 5 reports the key findings of the panel regressions of life expectancy (LE) on the financial inclusion (FI). All the models control for population growth. For Pooled OLS model, the FI has a positive sign and statistically significant at $1 \%$ level, suggesting that the importance of FI on LE is not small. Population growth rate (PG), on the other hand, is also strongly but negatively associated with longevity. For example, the coefficient 0.01 suggests that a $1 \%$ rise in population growth in Africa leads to $1 \%$ decline in life expectancy.

For both Fixed Effect (FE) and Random Effect (RE) models, the magnitude and significance of the effects of financial inclusion on longevity are also similar. The coefficient 0.006 for life expectancy (LE) suggests that a $1 \%$ rise in financial inclusion would increase longevity by $0.6 \%$ for FE model; and 1\% increase in numbers of depositors with commercial banks (the financial inclusion) related with life expectancy at $1 \%$ level for RE model. These findings suggest the need to test for heterogeneity among the three models - POLS, FE and RE models.

Table-5. Estimation Results for Financial Inclusion

\begin{tabular}{l|c|c|c}
\hline Variables & POLS & Fixed Effects & Random Effects \\
\hline Financial Inclusion & $0.0098^{* * *}$ & $0.0063^{* * *}$ & $(0.0006)$ \\
& $(0.0009)$ & $1.3748^{* * *}$ & $(0.0006)$ \\
\hline Population Growth Rate & $-0.8144^{* *}$ & $(0.4011)$ & $0.9702^{* * *}$ \\
& $(0.3809)$ & $54.49^{* * *}$ & $(0.3775)$ \\
\hline Constant & $58.89^{* * *}$ & $(0.9911)$ & $55.36^{* * *}$ \\
& $(1.1625)$ & 468 & $(1.3183)$ \\
\hline Observations & 468 & 63.57 & 468 \\
\hline F-statistics & 110.89 & 0.0000 & 0.0000 \\
\hline Probability & 0.0000 & & 134.67 \\
\hline
\end{tabular}

Note: *** denotes significant at $1 \%$ level and ** indicate significant at $5 \%$. Standard errors are reported in parentheses.

Source: Author's Compilation from STATA 13.

\subsection{Heterogeneity Test: Breusch-Pagan Lagrange Multiplier}

Generally, the likelihood ratio statistics as indicated by F-statistics (110.9 for POLS, 63.6 for FE and 134.7 for $\mathrm{RE})$ was highly significant at probability $(\mathrm{p}<0.0000)$ suggesting that all models have a strong explaining power. 
The estimation findings as shown in Table 5 was based on three models - POLS, FE and RE models. The POLS model assumed that all countries in Africa are the same; however, severe biases can arise if households are pooled because it suggests that there are no unique attributes of individual nations within the African continent. Such assumption is highly restrictive in a panel with heterogeneous countries.

Hence to check the homogeneity or heterogeneity of the nations in Africa, Breusch-Pagan LM test was employed following the study of Molla et al. (2017). The null hypothesis $\left(\mathrm{H}_{\mathrm{o}}\right)$ of the test is homoskedasticity of nations in Africa, that is, POL might be the appropriate model.

Table-6. Homogeneity Test Results.

\begin{tabular}{|c|c|c|}
\hline Estimated Results & Var & SD = Sqrt (Var) \\
\hline $\mathrm{LE}$ & 50.53 & 7.11 \\
\hline $\mathrm{e}$ & 6.05 & 2.46 \\
\hline
\end{tabular}

Note: Since the p-value of Breusch-Pagan LM test is very low (for instance, $<0.001$ ), the model is heterogenous.

Source: Researcher's Computation using Stata 13.

The results of Breusch-Pagan LM tests with the p-values of 0.0000 as shown in Table 6 was very low as the model does not suffer from heteroskedasticity. The computed value of likelihood ratio and Wald tests are 1,809.7, this further demonstrated that the model is not homogeneous as $\mathrm{H}_{\mathrm{o}}$ assumed. Thus, the study concluded that all the 36 countries in Africa were heterogeneous; that is, POL model is insignificant to explain the impact of financial inclusion on longevity in Africa. This was consistent with the studies of Novignon et al. (2015) that nations in Africa are not the same.

\subsection{Hausman Specification Test}

The FE models assumed there are unique attributes of individual nations in Africa, thus suggest the use of Least Square Dummy Variable (LSDV). RE model assumed there are unique time constant attributes of nations that are not correlated. Thus, to specify the appropriate model between FE and RE, Hausman test was applied. The null hypotheses $\left(\mathrm{H}_{\mathrm{o}}\right)$ for Hausman test is that RE model is appropriate and consistent when the p-value is high, against the alternate $\left(\mathrm{H}_{1}\right)$ of $\mathrm{FE}$ model is consistent when p-value is close to zero. From the Table 7 , since the pvalue of the Hausman test is as low as 0.0018 , the study assumed FE model is more consistent and appropriate.

Table-7. Hausman Test Results.

\begin{tabular}{c|c}
\hline \multicolumn{1}{c}{ Chi-squared } & 12.68 \\
\hline Prob & 0.0018 \\
\hline Source: Researcher's Preparation.
\end{tabular}

\subsection{Robustness Checks}

The study checked if the results were sensitive to exclusion of single countries. The findings were robust against this check. Similarly, the paper estimated the models with financial inclusion lagged by one-year. The findings did not change in any significant manner.

\subsection{Discussion of Findings}

Several evidence has revealed that African countries lagged behind in the attainment of health-related targets of the recent past MDGs; Perhaps because most Africans depend largely on out-of-pocket payments for medicalcare services during their health shocks experiences. Therefore, this study proposed an analytical framework to analyze how financial inclusion affects longevity in Africa. The main conclusions drawn from fixed effects model is that there is an indication that numbers of depositors with commercial banks (the financial inclusion) directly and significantly predicts longevity in Africa. However, rise in population growth have a significant role to reduce average life expectancy in Africa.

The results shed new light on the Grossman (1972) argument that various factors that determines the health of citizens. A potential explanation to the study's findings is that the paper's findings differ in that I focused only on the developing countries (Africa); and I use panel data models which allow controlling for unobserved country heterogeneity. The findings on financial inclusion is consistent with prior research (Dorfleitner and Rößle, 2018). Though the mechanisms through which financial inclusion increases longevity might be through access to financial resources and savings; however, financial inclusion is strongly linked to longevity in Africa. It is possible that societies with inadequate financial inclusion might have to struggle more in order to maintain their health in periods of health shocks.

\section{Conclusion, Policy Implications and Recommendations}

The findings of the study show that in developing countries especially in Africa, financial inclusion has an important effect on life expectancy. Given the importance of longevity on welfare as well as sustainability of an economy, financial inclusion associated with African's citizens inability to access timely and appropriate healthcare services during the periods of health shocks. Notably, all citizens that experience health shocks are frequently affected by income loss because of their inability to work and needs for medical-care treatment payments. For the panel regression models, financial inclusive improve longevity by $0.06 \%$ in Africa. The findings therefore suggest that for policy makers to improve longevity in developing countries, policies should focus on increasing the numbers of depositors (adults) with banks accounts.

Further studies could also focus on the effects of internet in terms of the cost of transactions, distance, and time to access financial activities via the use of mobile and the ATM on health in Africa. This is suggested because, it has implication to increase the capacities of credit delivery in remote areas and to access healthcare services. 


\section{References}

Alam, K. and A. Mahal, 2014. Economic impacts of health shocks on households in low and middle-income countries. A Review of Literature. Globalization and Health, 10(21): 1-18.

Dake, F.A., 2018. Examining equity in health insurance coverage: an analysis of Ghana's national health insurance scheme. International Journal for Equity in Health, 17(1): 1-10.Available at: https://doi.org/10.1186/s12939-018-0793-1.

Dorfleitner, G. and F. Rößle, 2018. The financial performance of the health care industry: A global, regional and industry specific empirical investigation. European Journal of Health Economics, 19(4): 585-594.Available at: https://doi.org/10.1007/s10198-017-0904-8.

Ellyne, M. and N. Mahlalela, 2017. The impact of remittances on poverty in Africa: A cross-country empirical analysis. The Paper Presented at the 14th African Finance Journal Conference, 17-18 May, 2017, Victoria Fall, Zimbabwe.

Grossman, M., 1972. On the concept of health capital and the demand for health. The Journal of Political Economy, 80(2): 223-255.Available at: https://doi.org/10.1086/259880.

Leivea, A. and K. Xub, 2008. Coping with out-of-pocket health payments: Empirical evidence from 15 African countries. Bulletin of the World Health Organization, 86(11): 849-856.Available at: https://doi.org/10.2471/blt.07.049403.

Love, I. and M.M.S. Peria, 2012. How bank competition affects firms' access to finance. World Bank Policy Research Working Paper, No. 6163

Molla, A.A., C. Chi and A.L.N. Mondaca, 2017. Predictors of high out-of-pocket healthcare expenditure: An analysis using bangladesh household income and expenditure survey, 2010. BMC Health Services Research, 17(1): 94.Available at: https://doi.org/10.1186/s12913-017-2047-0.

Naceur, S.B., A. Barajas and A. Massara, 2015. Can islamic banking increase financial inclusion? , Washington: International Monetary Fund (IMF).

Novignon, J., J. Nonvignon and E. Arthur, 2015. Health status and labour force participation in Sub-Saharan Africa: A dynamic panel data analysis. African Development Review, 27(1): 14-26.Available at: https://doi.org/10.1111/1467-8268.12119.

Okoroafor, D.O., A.S. Oluseyi and A. Emmanuel, 2018. Empirical analysis of the determinants of financial Inclusion in Nigeria: $1990-2016$. Journal of Finance and Economics, 6(1): 19-25.

Pesaran, M.H., Y. Shin and R.P. Smith, 1999. Pooled mean group estimation of dynamic heterogeneous panels. Journal of the American Statistical Association, 94(446): 62 1-634.Available at: https://doi.org/10.1080/01621459.1999.10474156.

WHO, 2017a. Fact sheet on cholera. Geneva, Switzerland: World Health Organization.

WHO, 2017b. Levels and trends in child mortality report for 2017. Geneva, Switzerland: WHO

WHO, 2018. WHO statistics 2018: Monitoring health for the SDGs. Geneva: WHO.

Witter, S., V. Govender, T.S. Ravindran and R. Yates, 2017. Minding the gaps: Health financing, universal health coverage and gender. Health Policy and Planning, 32(suppl_5): v4-v12.Available at: https://doi.org/10.1093/heapol/czx063.

World Bank, 2018. World development indicators. Washington DC: World Bank. 